\title{
Adaptation of gaming features for motivating learners
}

\author{
Baptiste Monterrat ${ }^{1}$, Élise Lavoué ${ }^{2}$, and Sébastien George ${ }^{3}$ \\ ${ }^{1}$ INSA-Lyon, LIRIS, UMR5205, F-69621, Lyon, France \\ ${ }^{2}$ IAE Lyon, Université Jean Moulin Lyon 3 \\ LIRIS, CNRS5205, F-69008 Lyon, France \\ ${ }^{3}$ LUNAM Université, Université du Maine, EA 4023, LIUM 72085 Le Mans, France
}

\begin{abstract}
.
Background. Many learning environments are quickly deserted by learners, even if they are efficient. Gamification of learning environments is a recent approach used to enhance learners' motivation and participation.

Aim. One issue with this approach is that people have various expectations and react differently faced with specific game mechanics. So, an important goal lies in automatically adapting game mechanics according to player types. In this paper, we study the gaming features that can be adapted in learning environments and the player model that can be used for the adaptation process. We propose an approach that aims to predict to which game mechanics a user is responsive, and to adapt the gaming features of the system according to this information.
\end{abstract}

Methodology. An implementation was released, and evaluated through an exploratory study with 59 middle school students, each one using the learning environment during three 45minutes sessions.

Results. The results validate the implementation of the system and show that the users' activity can help to predict their profile. The adaptation process did not improve learners' engagement as expected, but it shows a path for future research toward an adaptive approach for learning environment gamification.

Keywords. Gamification, Web-based Learning, Adaptation, Gaming features, Motivation, Player Model

\section{Introduction}

A large number of studies conducted in the technology-enhanced learning domain tends to make learning environments more efficient. However, learning activities are not always motivating for learners, and the drop-out rate is still high, specifically for remote activities. In this paper, we are interested in gamification in order to address learners' motivation problems when using a learning environment. We more particularly study the context of training memory, e.g. learning multiplication tables, vocabulary, word spelling or historical dates. This kind of activity is not very motivating in itself and the risk that learners drop out in this context is great. Since motivated learners set up better mental strategies for 
memorizing (Fenouillet and Tomeh, 1998), motivation is an essential prerequisite for success in this kind of learning activity.

Gamification is currently used to increase motivation in various contexts, such as business (Conley and Donaldson, 2015), work (Cheng et al., 2011), education (Kapp, 2012; $\mathrm{Su}$, and Cheng, 2015) and health (McCallum, 2012). In our work, we are interested in the use of gamification with online learning environments. The gamification approach relies on integration of individual game elements or meaningful combinations of those elements (Landers, 2015). Studies conducted over the past years show the effectiveness of gamification on learners' performances, motivation and participation with learning environments (Domínguez, Saenz-de-Navarrete, de-Marcos, Fernández-Sanz, Pagés and Martínez-Herráiz, 2013; De Marcos, Garcia-Lopez and Garcia-Cabot, 2016). These studies rely on the integration of several game elements in the learning environment (e.g. badges, leaderboards, points) and do not provide any information on the impact of a specific element on users according to their profile and preferences. However, we agree with Harviainen (2014) that "the very elements that motivate some learners (e.g., competition) are the ones disliked by others, and also those that when taken to excess, cause problems".

Some studies evaluate in more detail the impact on learners of a specific game element. For instance, Landers, Bauer and Callan (2015) showed the effectiveness of leaderboards on task performance and goal setting. Hanus and Fox (2015) showed that the integration of a leaderboard and badges in a learning environment decreased learners' motivation and performances in the final exam. In the study conducted by Hamari (2015), the use of badges increased learner activity. These results are coherent with the results of the study conducted by Da Rocha Seixas, Gomes and de Melo Filho (2016), which show that use of badges increased learners' performances.

These recent studies lead to significant progress in the field of gamification in several areas, including the educational domain (Hamari et al., 2014, Seaborn and Fels, 2015). However, gamification lacks the adaptivity required to reach a wide range of users (Vassileva, 2012) and to correspond to learners' game mechanism preferences (Harviainen, 2014). Little is known on how adaptation of game elements can be applied in computer-based environments. However, users have different types of engaged-behaviors when interacting with online environments (Bouvier, Sehaba and Lavoué, 2014) and different player preferences (Bartle, 1996). According to the gamification approach, we aim at integrating and adapting gaming features in existing learning environments according to player types. We consider gaming features as elements presented on the user interface so as to make the learning activity more engaging, without interfering with this activity. For instance, badges can be awarded for learners' accomplishments, but without changing the learning scenario.

Therefore, this paper aims at proposing a generic model and a process to increase learners' motivation, by gamifying their learning environment in an adaptive way. The proposed model allows selection of gaming features according to players' game mechanics preferences. These preferences are identified by means of a questionnaire based on the BrainHex gamer typology (Nacke et al., 2011). The proposed adaptation process has been implemented in an existing learning environment, named Projet Voltaire ${ }^{1}$, which aims to teach French spelling and grammatical rules to learners, at various levels of education. We developed three gaming features and tested the adaptation process with 59 middle school students. This exploratory study was designed to find out whether the proposed adaptation and profiling strategy can increase learners' motivation.

Section 2 is dedicated to the state of the art in gamification and its adaptation in the learning context. We present in section 3 a generic architecture to gamify learning

\footnotetext{
${ }^{1}$ Available on $w w w$.projet-voltaire.fr
} 
environments and an adaptation process to adapt gaming features to the player profile. Section 4 presents the results of a user study as well as a discussion on these results. Finally, we sum up in section 5 the main findings of the study and detail our future works.

\section{State of the Art}

Very little research concerns making gamification adaptive (Ferro et al., 2013). Accordingly, we study in this section the gamification elements that can be adapted (part 2.1) and, more generally, the player models (part 2.2). As little research has been conducted for adaptation in gamification, we study the adaptation processes (part 2.3) proposed in learning games that can be used for adaptive gamification.

\subsection{Adaptable Gamification Elements}

In this part, we study game elements used in gamification in order to establish how they can be adapted. The concept of "game element" appears to be very broad, including a wide range of concepts borrowed from gaming.

Authors generally provide detailed lists of elements with their functions in various gamification settings without differentiating the game mechanics, the design principles and the features that appear on the user interface. For instance, Vassileva et al. (2012) conducted a review of the literature on game mechanics, collecting patterns, rules and feedback loops that can be applied to develop game-like elements in virtual applications. They give examples of such patterns: ownership (such as points, tokens, badges), achievements (a virtual or physical representation of having accomplished something), status (displaying a rank or level of a user), community collaboration and quests (challenges related to time-limit or competition). Robinson and Belloti (2013) propose a taxonomy of gamification elements without defining exactly the nature of a game element. According to them, a gamification element could be an objective, a social feature, an incentive or even a resource. Kapp (2012) also lists undifferentiated typical game elements like goals, rules, competition, cooperation, time, rewards, levels (player, game, difficulty), feedback, storytelling (hero's journey), aesthetics (harmony).

In our work, we aim at providing a generic adaptive gamification process that does not impact the learning activity. As such, we are interested only in game elements that can be removable from the user interface of the learning environment. For the design of such removable features, we rely on the concept of epiphytes (Pachet et al., 2014): systems that can only exist attached to another system. Giroux et al. (1995) define the relationship between an epiphyte advisor system and its host application according to four rules: (1) the epiphyte cannot exist without its host, (2) the host can exist without the epiphyte, (3) the host and the epiphyte have independent existences, and (4) the epiphyte does not affect the host. While the third rule can be difficult to implement, the other three are necessary if we expect the gaming features to be enabled and disabled without a negative impact on the learning activity.

To follow these rules, we base our work on the detailed typology of game design elements given by Deterding et al. (2011), from the more concrete to the more abstract:

- "Game interface design patterns" like badges and leaderboards,

- "Game design patterns and mechanics" like competition and time constraints,

- "Game design principles and heuristics" like enduring play and clear goals,

- "Game models" like the MDA framework (Mechanics, Dynamics, Aesthetics) developed by Hunicke, LeBlanc, and Zubek (2004),

- "Game design methods" like playtesting and playcentric design.

We think that adaptation should take place at the most concrete level, to imply direct changes in the user interface. According to the typology proposed by Deterding et al. (2011), 
only game interface design patterns can be adapted without changing the learning environment (i.e. the host). Sailer (2013) provides a list of typical game elements that "can be found on a surface level": points, badges, leaderboards, progress bars, performance graphs, quests, meaningful stories, avatars and profile development. As a concrete example of removable game element, Barata et al. (2013) introduced a leaderboard webpage in the learning environment Moodle in order to improve learners' participation. The leaderboard presents the level of the participants, their avatar, their achievements, and their number of experience points. Based on this approach, we propose in part 3.2 a definition of gaming features, as features presented on the user interface that can be adapted to and removed from the learning environment.

\subsection{User Models for Adaptation}

Adaptation of gaming features relies on a user model. Users of a gamified learning environment can be considered as learners (interacting with pedagogical activities) and as players (interacting with gaming features). According to Brusilovsky and Millán (2007), the user model in an adaptive educational hypermedia is mainly composed of six sub-models: user's goals, user's knowledge, user's interest, user's background, individual traits, and context of work. In our paper, we are particularly interested in users' individual traits as player types.

Players generally have favorite game types, and they feel engaged with some game mechanics but not all. For example, Bartle (1996) proposes a classification in four player types. This classification is one of the most well-known (killer, achiever, explorer, socializer), but is specific to massively multiplayer online role-playing games (MMORPG). More generally, Yee (2006) identifies three main motivation components: achievement, social and immersion. Based on a review of preview player type studies, Ferro et al. (2013) also distinguish five player types with a gamification approach: dominant, objectivist, humanist, inquisitive and creative. However, these typologies are not linked to practical tools (for instance a questionnaire) to identify users' player types. Thus they cannot be used for adaptation of gaming features.

One recent contribution in this area is the BrainHex gamer typology (Nacke et al., 2011). This classification includes seven player types based on insights from neurological findings:

- the Seeker enjoys discovery and exploration,

- the Survivor enjoys escaping and feeling fear,

- the Daredevil enjoys taking risks and playing on the edge,

- the Mastermind enjoys solving puzzles and devising strategies,

- the Conqueror enjoys defeating difficult opponents,

- the Socializer enjoys interacting with other players,

- the Achiever enjoys completing tasks.

Contrary to previous typologies, this one is not related to a specific game genre like MMORPG, so it is more likely to work with gamification. The BrainHex typology was applied successfully in the design of persuasive games for healthy behaviors (Orji et al., 2013). For these reasons, this classification is the one we selected as the player model for adaptive gamification. In addition, it is combined with an online survey ${ }^{2}$ conducted with more than 60,000 players. This survey can be used to assess users' player types in experimental conditions.

\footnotetext{
${ }^{2}$ Available on brainhex.com
} 
Although the BrainHex survey still has to be improved, it seems to be yet the most advanced player type survey. Its validity was investigated recently. Busch et al. (2016) measured the internal consistency of each of the seven factors underlying the test with Cronbach's Alpha $(n=592)$. They found acceptable reliability coefficients. They also evaluated the stability over time with a second questionnaire six month later $(n=243)$. The results show that some factors (in particular Seeker and Achiever) are not stable. However, stability is not critical in our approach, as we aim to develop a dynamic adaptation system, with frequent updates of the model.

\subsection{Relating Gaming Features and the Player Model}

To adapt the gaming features defined in part 2.1, their relationships to the player types presented in section 2.2 have to be established. Gauch et al. (2007) reviewed the main types of user model representations used for deciding which learning object is the most relevant for the learner: association rules, semantic networks and weighted keywords or concepts. We think that player types can be modeled in the same way as user profiles, by matching users to gaming features instead of learning objects. Association rules (Mobasher, 2007) are a data mining technique to make the model emerge from data. It could be used to generate an empirical model that makes associations between gaming features and player types. However, gaming formalism is not sufficiently advanced to create a comprehensive ontology of game concepts. With weighted keywords, "each profile is represented in the form of a keyword vector, and the documents (...) are converted to similar weighted keyword vector" (Gauch et $a l ., 2007)$. We decided to apply this approach to gaming features, by representing them as a vector of player types.

Once the links between game elements and player types have been established, they can be used to dynamically update the player model. Thue et al. (2008) used such a linear player model to generate the events of a story. Their adaptation process relies on two operations. During the first phase, they look at the player's actions to build his/her profile by using a map between the possible actions and the player model. During the second phase, the player profile was used to predict which story events will be more relevant for the player. Göbel et al. (2010) used a similar approach to adapt the learning contents, the game elements and the scenario of a learning game. Their model was based on Bartle's player types. The profiling operation was replaced by a survey on the players' preferences. Then the player profile was used to calculate a relevance score for each scene and to select the next game's scene. We will use the same operations to adapt the list of gaming features: profiling users based on their actions, and selecting gaming features based on their player model.

\section{Adaptable Gaming Features and Adaptation Process for Learning Environments}

In this part, we present the architecture, models and process for the adaptation of the gaming features proposed to learners in a learning environment. We also propose a list of rules for a gaming feature to be adaptable in this specific type of computer-based environment.

\subsection{General Architecture}

As explained in section 2.3, we distinguish two user model parts in a learning environment: the learner model (i.e. learners' knowledge and skills) and the player model (i.e. learners' preferences on game mechanisms). Our approach focuses on the player model adaptations and assumes that the learner model adaptations are possibly handled by the existing learning environment. We present the system architecture for a web-based learning environment in Figure 1. 


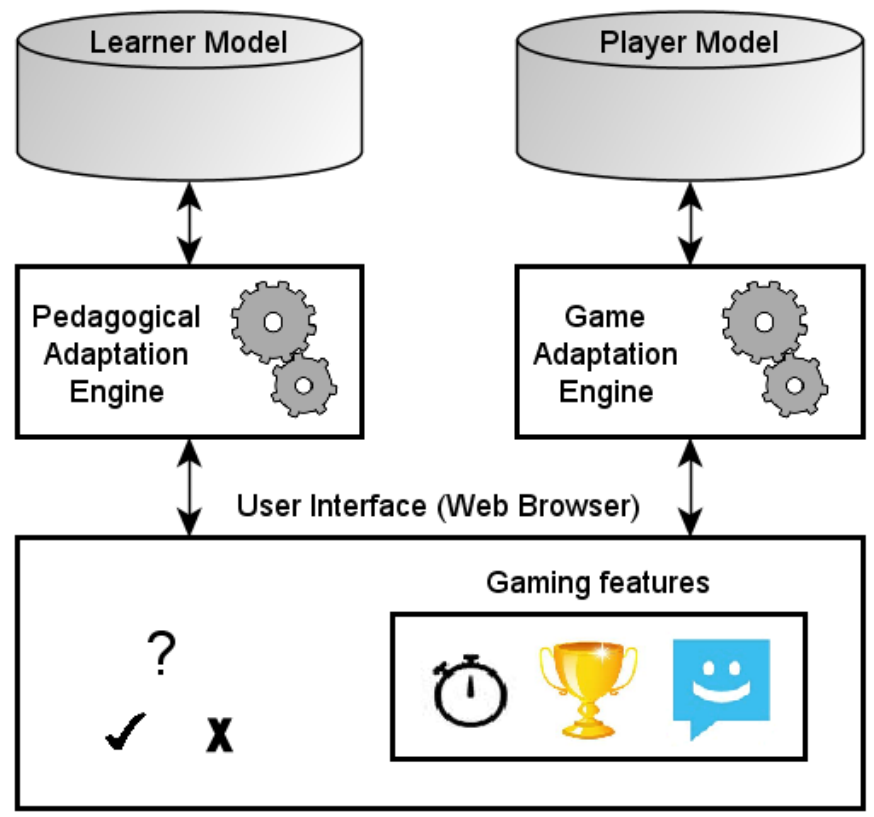

Figure 1: Architecture of a web-based learning environment with adaptive gamification

The eventual existing pedagogical engine and the learner model work on their own, and the adaptive gamification system does not interfere with them. For the player model, we propose a vector in $[0,1]^{7}$ with one value for each player type proposed in the BrainHex classification.

The relationships between the gaming features and the player types are expressed in a table in $[0,1]^{7 \mathrm{n}}$ where $\mathrm{n}$ is the number of gaming features. The values depend on the specific implementation of each gaming feature. 0 means that they are not related, while 1 means that they are highly related, like for instance the leaderboard and the conqueror player type. We will show in section 4 how this table could be defined.

The game adaptation engine plays two roles: updating the player model according to the user/system interactions, and selecting new gaming features for the user interface according to the player model. The game adaptation engine collects the user's actions in the learning environment from both the learning activity and the pedagogical elements. The "USE" event indicates that the user interacted with a gaming feature, while the "OFF" event indicates that the user decided to disable the gaming feature.

\subsection{Adaptable Gaming Features for Learning Environments}

In our work, the elements we consider for adaptation are gaming features. We define a gaming feature as an indivisible set of game interface design elements reifying a set of game mechanics. This can be a set of one or more elements, where the elements can imply one or more game mechanics. As an example, we can consider a challenge with winnable trophies, as developed by Domínguez et al. (2013).

However, adapting game elements in the user's environment includes various constraints. For instance, according to Thom et al. (2012), removing a gamification feature within a social networking system can have a negative impact on users' participation. Based on the state of the art, we propose hereafter a list of six rules (from R1 to R6) that gaming features must follow, in order to allow adaptive gamification. At first, each gaming feature should implement at least one game dynamics that match a player type of the gamer typology (R1), else it will not be possible to relate them to the players' preferences. Regarding the learning activity, Nicholson (2012) proposed a framework to make gaming features 
meaningful. He states that the features should be directly relevant to the user as a learner. That is why each gaming feature should be based on information related to the learner or the learning content (R2). As an example, the experience points in the leaderboard proposed by Barata et al. (2013) are derived from the learner model. This is a unilateral relationship, ensuring that the learner model remains independent of gamification.

Other rules are derived from the concept of epiphyte (Giroux et al., 1995) introduced in part 2.2. To ensure independence, the consistency of the host system and learning activity should not be affected when a disabled gaming feature becomes enabled (R3), or when an enabled feature becomes disabled (R4). We also state that learners should be provided with a way to disable the features (R5) due to the voluntary aspect of games introduced by Caillois (1961). Finally, as the players' profiles should be updated based on their interaction traces, gaming features should allow interactions with the learner, and these interactions should attest to the learners' interest in the feature (R6). A list of the six requirements for adaptive gaming features is given below:

- R1. They should implement at least one game dynamic corresponding to a player type;

- R2. They should be based on information related to the learner or the learning content;

- R3. They should not affect the consistency of the learning activity when enabled;

- R4. They should not affect the consistency of the learning activity when disabled;

- R5. The user should be provided with a way to disable them;

- R6. They should emit an event attesting to an interest by the user (traceability).

For instance, a leaderboard rewarding the user's number of consecutive good answers (R1) implements competition, corresponding to the Conqueror player types in the BrainHex model, (R2) encourages the user to focus on the learning activity by showing the number of correct answers, (R3) does not require extra work from the user, (R4) is not necessarily requisite for the learning activity, (R5) can be enhanced with a cross button to be hidden by the user, and (R6) can provide additional information when the mouse hovers (see section 4). As a counter-example, although a gaming feature can reward users with badges, these badges must not be requisite to unlock new levels in the learning environment. This would prevent the possibility of removing the badges, and break rules R3 and R4. Thus, adaptation to the level of difficulty is the responsibility of the existing environment with its learner model.

These 6 required rules have been defined basing us on the definition of an epiphyte system and on previous works on gamification. At this stage of the study, these 6 rules seem sufficient, but we do not exclude to add more depending on work progress and evaluation.

\subsection{Gaming Features Adaptation Process}

There are two main steps for adaptation of gaming features: profiling and adapting. First, for profiling, we use the interaction traces to predict the player's profile. Then, for adapting, we use the player's profile to select the next gaming feature to activate in the user's interface. In this part, we describe both algorithms, and examine the adaptation process in more detail.

\subsubsection{Player Profiling}

The player's profile is updated every time the user performs an interaction with a gaming element. The profiling algorithm inputs are:

- The last user's action ("USE" or "OFF"), 
- $\quad p p$ in $[0,1]^{7}$, the player profile before being updated,

- $r r$ in $[0,1]^{7 \mathrm{~g}}$, the table of relationships between the $g$ gaming features and the seven player types.

- $s_{\text {use }}$ and $s_{\text {off }}$ in $[0,1]$, the strength of the change.

The output is the new player profile after updating. The update is made according to the following rules:

- When the game adaptation engine receives the "USE" event, it applies the equation (1) to increase each value $p_{n}$ of the player profile $p p$ for each player type $n$ :

Eq. (1)

$$
p_{n}=p_{n}+\left(1-p_{n}\right) * s_{\text {use }} * r_{n g}
$$

- When the game adaptation engine receives the "OFF" event, it applies the equation (2) to decrease each value $p_{n}$ of the player profile $p p$ for each player type $n$ :

Eq. (2) $\quad p_{n}=p_{n}-p_{n} * s_{o f f} * r_{n g}$

In both cases, the player type values $p_{n}$ are affected by three coefficients. To understand them, we will consider here the situation with a user carrying out an interaction with a leaderboard feature.

- The first coefficient is the distance between the actual $p_{n}$ and the minimal/maximal value. With a "USE" action this implies that if the actual value is 0.9 , it will make a very small move toward 1 , but if the actual value is 0.1 , it will make a big move toward 1 . If the action was "OFF", the $p_{n}$ values will move toward 0 in the same way. This system allows every interaction to have an impact on the model, without going over 1 or under 0 .

- The second coefficient is the strength of the interaction $\left(s_{\text {use }}\right.$ or $\left.s_{\text {off }}\right)$. With a strength close to 0 , the $p_{n}$ values will make a small move, while with a strength close to 1 , the $p_{n}$ values will make a big move toward 0 . We recommend low strength values for frequent actions, and high values for rare actions which are indicative of the users' preferences.

- The third coefficient is the relationship between gaming feature $g$ and player type $n\left(r_{n g}\right)$. The leaderboard is strongly related to the Conqueror type $(\mathrm{r}$ Conqueror-Leaderboard $=1)$, but is not related to the Mastermind type $\left(\mathrm{r}_{- \text {Mastermind- }}\right.$ Leaderboard $=0$ ). Therefore, if a user disables the leaderboard, his/her $\mathrm{p}_{\text {Conqueror }}$ value will make a big move toward 0 , but his/her pastermind value will not change.

To illustrate the role of the strength $\left(s_{\text {use }}\right.$ and $\left.s_{\text {off }}\right)$, we can consider a case with an average initial profile value ( $\left.p_{\text {Conqueror }}=0.5\right)$, and an action that is highly related to this profile $\left(\mathrm{r}_{\text {-Conqueror-Leaderboard }}=1\right)$. If the "USE" of the leaderboard has a strength $s_{\text {use }}=0.9$, then the player profile will reach the value 0.95 after one interaction only, thus consider the player as highly conqueror. Otherwise if $s_{\text {use }}=0.1$, the same value 0.95 will be reached only after 22 interactions. Thus the right strength is determined by the expected number of interactions for a meaningful interest toward a given player profile.

\subsubsection{Adaptation to the Player Profile}

When the system introduces a new gaming feature to the user, the game adaptation engine calculates the corresponding relevance score based on the distance between the player vector and the gaming feature vector.

The inputs of the algorithms are:

- $\quad p p$ in $[0,1]^{7}$, the player profile before being updated, 
- $r r$ in $[0,1]^{7 \mathrm{~g}}$, the table of relationships between the $g$ gaming features and the seven player types.

The output is a relevance score for each gaming feature $\mathrm{g}$. The score is given by (3):

Eq. (3) $\quad \operatorname{score}(g)=\sum_{n=1}^{7}\left(r_{n g} \cdot p_{n}\right) / \sum_{n=1}^{7}\left(r_{n g}\right)$

These scores can be used to make recommendations to the user, or directly to integrate one of the highest ranked features into his/her interface.

The defined formula is based on a linear variation (matrix multiplication). We choose this kind of variation because such models have been used successfully, in particular in educational situations, as proposed by Desmarais, Beheshti and Naceur (2012). If we notice in the future certain limits or bias, we do not exclude to switch to another type of variations such as logarithmic or quadratic one.

\subsubsection{Linking Gaming Features to Player Types}

Both the player profiling process and the adaptation process rely on a table of relationships between the gaming features and player types. The attribution of such values is made by identifying which game mechanics emerge from a gaming feature, and defining if these mechanics match a given player type. This work is based on the description of the player types. For example, the description of the Conqueror type includes "Players fitting the Conqueror archetype enjoy defeating impossibly difficult foes, struggling until they achieve victory, and beating other players (...)" (Nacke et al., 2011). This description suggests these types of players enjoy competition. As a leaderboard implements competition, it will be related to the conqueror type with a value close to one. Considering a set of badges as a gaming feature, its rating will also be made according to the archetype description. If the badges are difficult to obtain, and push the players to struggle until they achieve victory, the relation value will be rather high. However, if the badges are all easy to obtain, the relation value between these badges and the conqueror type will be rather close to zero.

\section{Implementation and Exploratory Study}

We released an implementation of the system attached to the learning environment called Projet Voltaire. An exploratory study was conducted in a middle school in France to investigate three main research questions:

1. Can introducing more gaming features to a learning environment make it more complicated to use? Examining the effect of the number of gaming features on the complexity of the learning environment will bring new insight on the need for adaptive gamification.

2. Can a profiling strategy improve profile quality? We propose an implementation of our profiling strategy to study its impact in comparison with a random profiling.

3. Can adapted gaming features improve the learners' engagement with the learning environment? The impact of adaptation is measured based on users' perceived fun and usefulness and on the observation of interaction traces with the gaming features.

\subsection{Participants}

Three classes of middle school pupils participate to the study. The number of participants was 59 aged between 14 and 15 (28 boys and 31 girls). For the school, we gave a free access to the learning environment (which is generally not free) in exchange of their participation. For the students, the participation was included in their French lessons. Their participation was mandatory and they received no compensation. 


\subsection{Gamified Learning Environment}

We implemented the adaptation process and the models proposed in section 3 in the Projet Voltaire platform, which is an online learning environment to practice French spelling and grammatical rules. Training is based on asking the user to identify possible misspellings in sentences.

Three gaming features were implemented:

1. Bright stars.

2. A relative leaderboard.

3. A mnemonics-sharing feature.

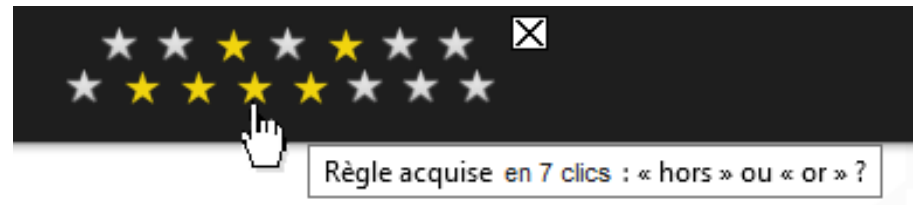

Figure 2: Screenshot of the bright stars (English translation of hint: "rule mastered after 7 clicks")

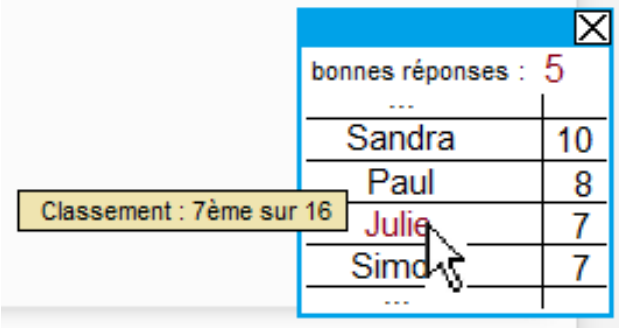

Figure 3: Screenshot of the leaderboard (English translation of hint: "Ranking: 7th over 16") Legend (First line: "good answers"; Tooltip: "Ranking: $7^{\text {th }}$ out of 16")

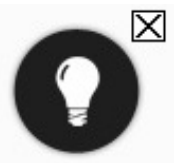

Figure 4: Screenshot of the button to access the mnemonics popup

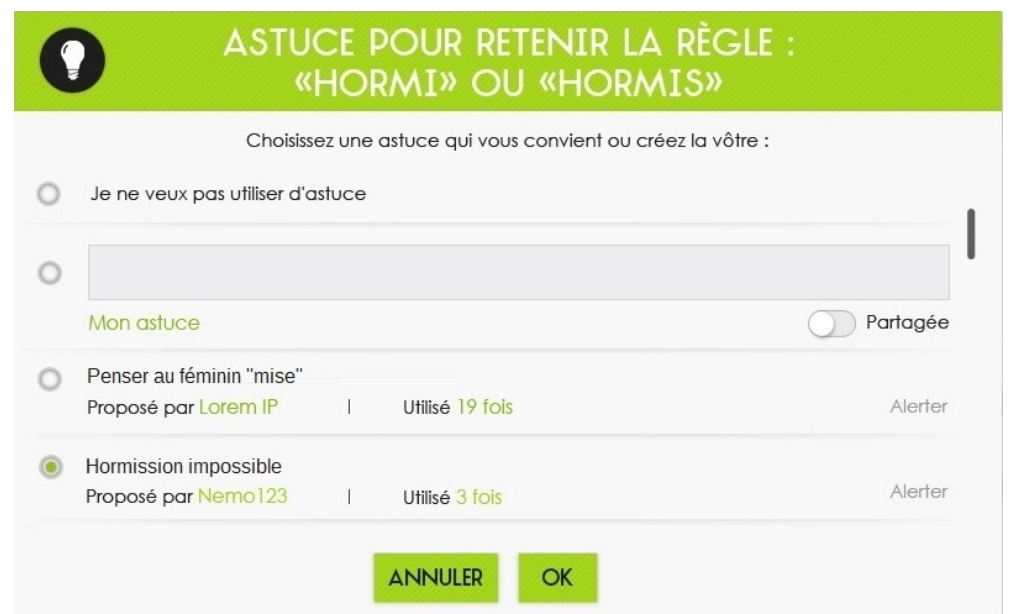

Figure 5: Screenshot of the mnemonics popup

Legend (Title: "Mnemonic to remember the rule"; Subtitle: "Select a mnemonic that suits you or create your own"; First line: "I don't want to use a mnemonic"; The second line is a text field to write a mnemonic; The other lines are mnemonics written by other users.) 
The bright stars gaming feature (see Figure 2) is made up of stars for each rule that the user has to learn in the level. The star turns from grey to yellow when the user masters its corresponding spelling rule.

We also developed a relative leaderboard (see Figure 3): the user can only see the two users just before him/her and the two users just after him/her. That way the user is encouraged to improve his/her rank step by step, which looks like a much more achievable challenge than trying to be ranked first. The score is the best number of consecutive correct answers provided.

Finally, we developed a feature for creating and sharing mnemonics (see Figure 4 and Figure 5). After each answer, the user can access a popup to perform one of these actions:

- Writing a mnemonic to help remember the spelling rule,

- Sharing the written mnemonic with others,

- Selecting a mnemonic written by somebody else.

The user is also provided with the number of users who read his/her mnemonics. This can be perceived as social recognition for his/her contribution.

We assume that three features allow the adaptation possibilities of the system to be tested. In fact, these features cover several types of player preferences. While designing the features, we made sure they would implement mechanics that were as different as possible, in order to cover distinct player types. Table 1 represents the relationships rr between the features and player types.

Table 1: Relationships $r r$ between the features and player types

\begin{tabular}{|l|c|c|c|c|c|c|c|}
\hline & Seeker & Survivor & Daredevil & Mastermind & Conqueror & Socializer & Achiever \\
\hline Bright stars & 0.2 & 0 & 0.2 & 0.2 & 0 & 0 & 1 \\
\hline Leaderboard & 0.2 & 0.3 & 0.7 & 0 & 1 & 0.5 & 0.5 \\
\hline Mnemonics & 0.6 & 0 & 0 & 0.8 & 0.3 & 1 & 0 \\
\hline
\end{tabular}

Table 1 shows that each feature is highly related to at least one player type, which is required to respect the rule (R1). Each feature is related to the learning activity (R2), as features 1 and 2 award the user for good answers, and feature 3 for contributions related to the learning content. We also made sure that enabling and disabling the features does not affect the consistency of the learning activity (R3, R4). Then we added a cross button in the top right corner of each feature to allow the user to disable it (R5), thus triggering the "OFF" event. Finally, we made sure that each feature generates an interaction that can be tracked by the system (R6).

\subsection{Materials and Measures}

\subsubsection{Traces of interactions}

All the interactions between the students and the game features were tracked. Also, the gaming features were developed specifically to suggest possible interactions with the user ("USE") or to be disabled ("OFF").

For the first feature, when the user moved the cursor over a yellow star, he/she could know how many answers he/she made before mastering the rule. This action triggered a "USE 1" event. For the second feature, the "USE 2" event was also triggered by hovering the game element. Passing the cursor over the Leaderboard was the only way to know his/her global ranking. Finally, the "USE 3" event was triggered by all the actions related to the mnemonics feature: writing, sharing, selecting. 


\subsubsection{Questionnaires}

The player profile of the students was assessed with a French translation of the BrainHex Questionnaire. This questionnaire is made of 28 items: including four items related to each player type of the typology. Among these questions, 21 can be answered on a scale from -4 to 2 . The seven other items are statements that have to be sorted, to make scores from 2 to 14 . The complete survey gives a score comprised in $[-10 ; 20]$ for each player type.

The original survey is available on the BrainHex website (BrainHex, 2011). Our version of the survey is available as an appendix of this paper. Some items were adapted to gamification: people who are not used to play games should be able to imagine themselves in the proposed situations.

Table 2: Internal consistency of the BrainHex survey with Cronbach's Alpha

\begin{tabular}{|l|c|c|c|c|c|c|c|}
\hline Factor & Seeker & Survivor & Daredevil & Mastermind & Conqueror & Socializer & Achiever \\
\hline CA (3 items) & 0.23 & 0.38 & 0.38 & 0.41 & 0.17 & 0.31 & 0.25 \\
\hline
\end{tabular}

We report in Table 2 the Cronbach's Alpha of the player type survey, based on the three multiple-choice items of each factor. The values obtained are low (from 0.17 to 0.41 ). We discuss this result in section 4.5.1.

A final questionnaire was made to assess the perceived complexity of the system, the perceived usefulness and fun of the gaming features. The statements were:

- "I think Projet Voltaire is too complicated to use?"

and for each used feature:

- "This feature was useful."

- "This feature was fun."

Each statement could be rated on a four-points scale: "no" (0), "rather no" (1), "rather yes" (2), and "yes" (3).

\subsubsection{Analysis tools}

Given our sample sizes ( 8 to 17 participants per group), statistical tests can give interesting p-values only with very strong effects. Also, the risk of type I and type II error is high with small sample sizes. Accordingly, we will not perform statistical tests on the results of this exploratory experiment. We will rather describe the differences between groups with Cohen's d-value (Cohen, 1977) with pooled standard deviation.

\subsection{Procedure}

Six groups of learners were available for the experiment. The groups had been made by the professors by splitting the three classrooms in two. Each group was randomly assigned to one of our five experimental conditions, with two groups for the first condition (P). The variations in group size were due to some unforeseen absences of learners.

- Group P: 17 learners had the three features in their environment.

- Group A: 10 learners received the feature that best matches their BrainHex profile.

- Group B: 13 learners received the feature that worst matches their BrainHex profile.

- Group C: 11 learners received one feature selected randomly.

- Group D: 8 learners did not receive any features. 
The participants filled in the BrainHex questionnaire. Then they used Projet Voltaire for three 45-minute sessions, with a one-week interval between sessions. The gaming features were activated only in the second and third sessions. The learning sessions took place in the classroom using the school computers. The learners' teachers were present to guide them. Finally, at the end of the last session, the learners received the final questionnaire, about their enjoyment of the gaming features and the perceived complexity of the system.

Table 3: Distribution of the gaming features

\begin{tabular}{|l|l|l|c|l|c|}
\hline & Group P & Group A & Group B & Group C & Group D \\
\hline Conditions & $\begin{array}{l}\text { The three } \\
\text { features }\end{array}$ & $\begin{array}{l}\text { The best match } \\
\text { feature }\end{array}$ & $\begin{array}{l}\text { The worst } \\
\text { match feature }\end{array}$ & $\begin{array}{l}\text { A random } \\
\text { feature }\end{array}$ & No feature \\
\hline $\begin{array}{l}\text { Number of } \\
\text { members }\end{array}$ & 17 & 10 & 13 & 11 & 8 \\
\hline Stars & 17 & 3 & 4 & 4 & 0 \\
\hline Leaderboard & 17 & 3 & 6 & 4 & 0 \\
\hline Mnemonics & 17 & 4 & 3 & 3 & 0 \\
\hline
\end{tabular}

Table 3 shows how the gaming features are distributed within the groups, after applying the adaptation algorithm.

To investigate the first research question (complexity), we used the results of all groups of learners as well as their answers about system complexity.

For the members of group $\mathrm{P}$, the profile was initialized where $p_{n}=0.5$ for all player types. Then the system ran the profiling algorithm on their interaction traces. To evaluate the second research question (profiling), we compared the accuracy of the profiles resulting from this process with the accuracy of random profiles.

For groups A, B, the results of the BrainHex survey were used instead of the profiling algorithm to set the initial state of their player models. We used the adaptation equation to calculate the relevance scores of the gaming features. The answers to the final questionnaire of groups A, B, C and D were used to study the third research question (adapting).

\subsection{Results}

\subsubsection{Participant Profiles}

All the participants completed the BrainHex survey. Table 4 presents the dominant player types predicted by the survey. These data show a strong dominance of the Conqueror type $(39 \%)$ and a near absence of the Seekers $(2 \%)$, while the other player type preferences are quite evenly distributed between the learners ( $8 \%$ to $15 \%)$.

Table 4: Dominant player types

\begin{tabular}{|l|c|c|c|c|}
\hline & $\begin{array}{l}\text { Profiling } \\
(\mathrm{P})\end{array}$ & $\begin{array}{l}\text { Adapting } \\
(\mathrm{A}, \mathrm{B}, \mathrm{C}, \mathrm{D})\end{array}$ & $\begin{array}{l}\text { All groups } \\
(\mathrm{A}, \mathrm{B}, \mathrm{C}, \mathrm{D}, \mathrm{P})\end{array}$ & $\begin{array}{l}\text { Original } \\
\text { BrainHex test }\end{array}$ \\
\hline Seeker & $\mathrm{n}=17$ & $\mathrm{n}=42$ & $\mathrm{n}=59$ & $\mathrm{n}=50,428$ \\
\hline Survivor & $0 \%$ & $2 \%$ & $2 \%$ & $19 \%$ \\
\hline Daredevil & $12 \%$ & $10 \%$ & $10 \%$ & $7 \%$ \\
\hline Mastermind & $6 \%$ & $14 \%$ & $12 \%$ & $6 \%$ \\
\hline Conqueror & $47 \%$ & $10 \%$ & $8 \%$ & $20 \%$ \\
\hline Socializer & $18 \%$ & $36 \%$ & $39 \%$ & $28 \%$ \\
\hline Achiever & $12 \%$ & $17 \%$ & $14 \%$ & $10 \%$ \\
\hline
\end{tabular}




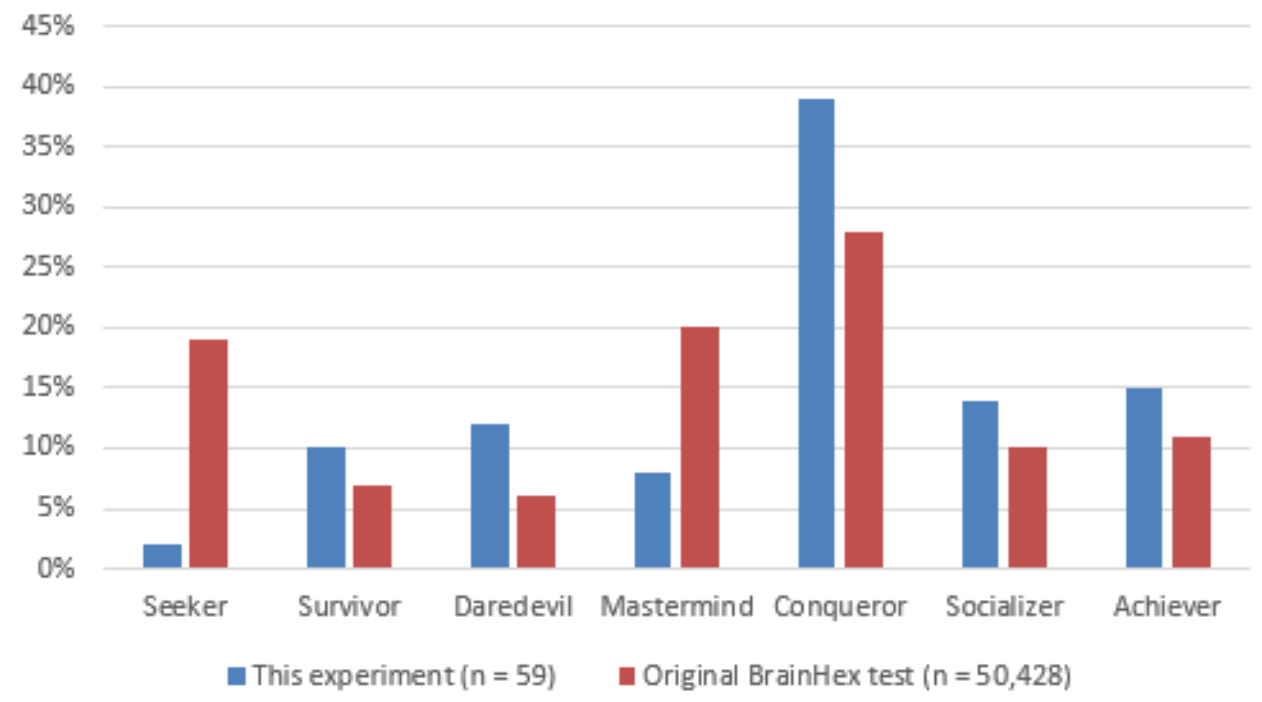

Figure 6: Dominant BrainHex types in our population and in the original BrainHex test

In 2010, the creators of BrainHex processed the first 50428 responses received on their online survey (BrainHex, 2011). Although no information is given on their population, the number of participants makes it interesting as a comparison. We compare their original results and ours on Figure 6. The Conqueror type was also the most represented, but to a lesser extent $(+11 \%)$. The comparison also shows that the low number of Seekers and Masterminds is specific to our population ( $-17 \%$ and $-12 \%)$. That being said, our experiment does not aim to generalize the player types for a population and only seek to study the impact of the adaptation process.

The results of this survey could be questioned because of the low alpha values we obtained (see table 2). This effect does not come from the original survey, as Busch et al. (2016) found acceptable alpha values (from 0.63 to 0.78 ). We discuss this point in the limitations of the study (see section 5.3).

\subsubsection{Complexity of Gaming Features}

The participants were asked whether or not they found Projet Voltaire too complicated to use on a scale from 0 to 3 . We compared the answers according to the number of gaming features in the environment. The results are plotted on Table 5 and Figure 7 . We specify that the number of answers is different from the total number of participants, as 18 students were missing when filling in the final survey.

Table 5: Answers to the question: "Is Projet Voltaire too complicated to use?"

\begin{tabular}{|l|l|l|l|c|c|c|c|}
\hline $\begin{array}{l}\mathrm{Nb} \\
\text { features }\end{array}$ & Group & $\begin{array}{l}\text { no } \\
(0)\end{array}$ & $\begin{array}{l}\text { rather no } \\
(1)\end{array}$ & $\begin{array}{l}\text { rather yes } \\
(2)\end{array}$ & $\begin{array}{l}\text { yes } \\
(3)\end{array}$ & Mean & Std. dev. \\
\hline 0 & Group D (n=5) & $60 \%$ & $20 \%$ & $20 \%$ & $0 \%$ & 0.6 & 0.7 \\
\hline 1 & Groups A B C (n =25) & $40 \%$ & $24 \%$ & $24 \%$ & $12 \%$ & 1.1 & 0.9 \\
\hline 3 & Group P (n=11) & $27 \%$ & $27 \%$ & $18 \%$ & $27 \%$ & 1.5 & 1.0 \\
\hline
\end{tabular}

With no feature, $60 \%$ of users reported that the environment was not complicated ( 0 ) to use and no user rated it as complicated (3). However, as the number of features increases, the perceived complexity becomes higher. The effect size is notable, with a d-value equal to 0.60 between zero and one feature, and 0.42 between one and three features. 


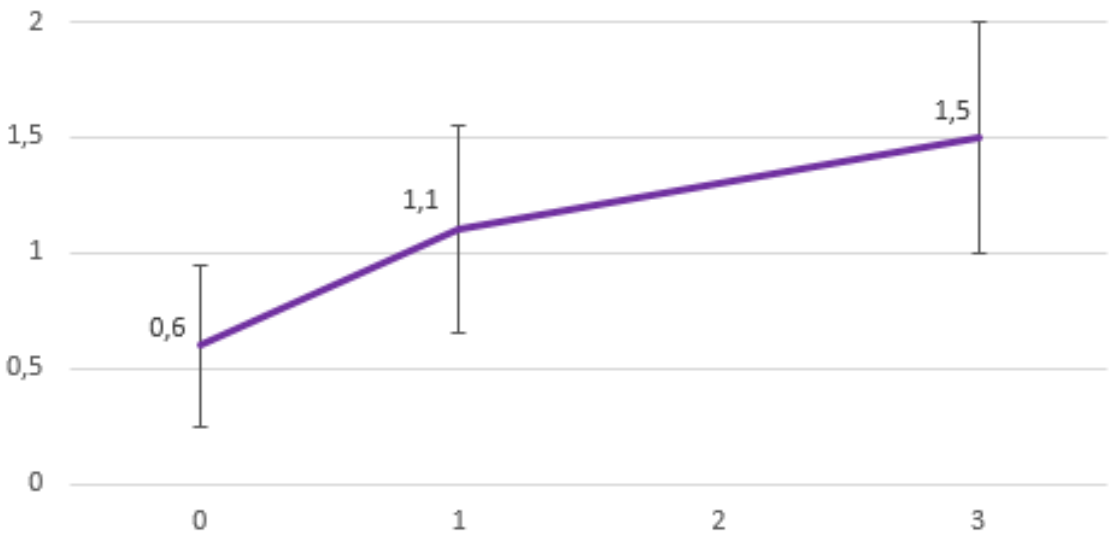

Figure 7: Answers to the question: "Is Projet Voltaire too complicated to use?" according to the number of features

\subsubsection{Feature Preferences}

We observed the use of the gaming features by the learners based on the interaction traces. The average number of "USE" and "OFF" events triggered per student during the experiment are shown on Figure 8. We observe that the leaderboard was the most used feature, but also that it was closed relatively often, just like the mnemonics feature. We think it important to note that the leaderboard appeared in the middle of the screen at the beginning of the second session. The teachers reported that several participants considered it to be an annoying popup and closed it before watching its content.

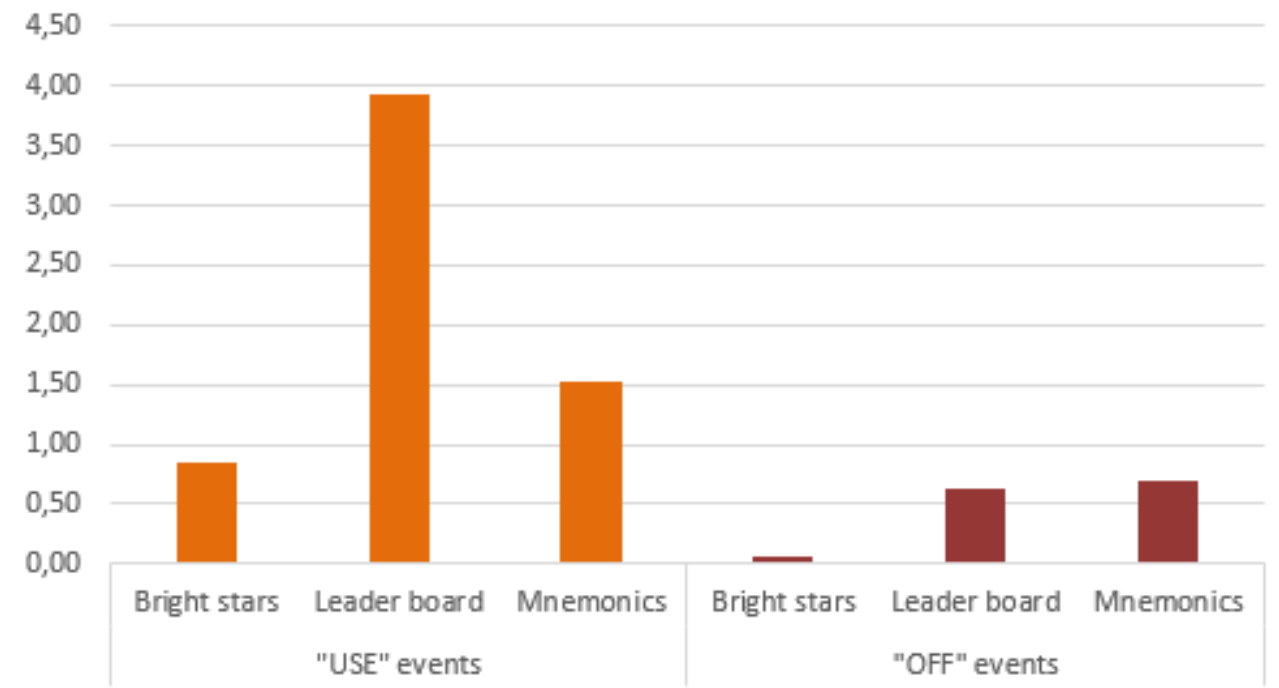

Figure 8: Average number of gaming features interactions per user

Legend (For each gaming feature, only the users having this feature in their interface are considered for the ratio.)

In the final survey, the learners were asked how useful and how funny they found the feature they had, on a scale from 0 to 3. The results are reported in Figure 9. The effect size is reported in Table 6. 


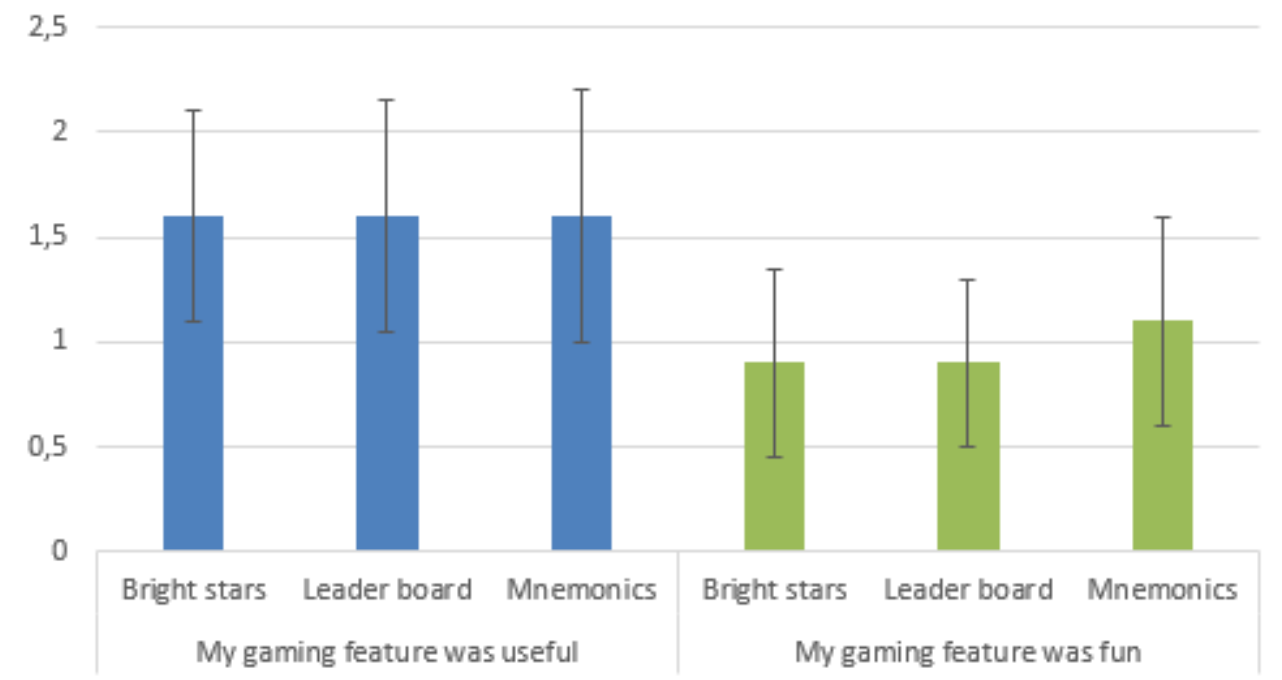

Figure 9: Perceived usefulness and fun of gaming features across features

Table 6: d-value for the perceived usefulness and fun of gaming features across features

\begin{tabular}{|c|c|c|c|c|c|c|}
\hline & \multicolumn{3}{|c|}{ My gaming feature was useful } & \multicolumn{3}{|c|}{ My gaming feature was fun } \\
\hline$<$ & $\begin{array}{l}\text { Bright } \\
\text { stars }\end{array}$ & $\begin{array}{l}\text { Leader } \\
\text { board }\end{array}$ & Mnemonics & $\begin{array}{l}\text { Bright } \\
\text { stars }\end{array}$ & $\begin{array}{l}\text { Leader } \\
\text { board }\end{array}$ & Mnemonics \\
\hline Bright stars & 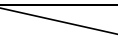 & 0 & 0 & $\bar{E}$ & 0 & 0.21 \\
\hline Leader board & 0 & 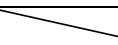 & 0 & 0 & & 0.22 \\
\hline Mnemonics & 0 & 0 & 2 & -0.21 & -0.22 & \\
\hline
\end{tabular}

The mean values report no differences among features for their perceived usefulness $(\mathrm{m}=1.6)$, and enjoyment $(\mathrm{m}=0.9$ and $\mathrm{m}=1.1)$, with $\mathrm{d}$-values close or equal to zero. However, the large standard deviation reflects great differences among users. These differences suggest that participants have different preferences in term of gaming features. This result is coherent with the different player profiles identified in previous part. Another interesting result is that all groups perceived the gaming features as being more "useful" than "fun". We could expect the contrary with the integration of gaming features into learning environment. Nevertheless, this result is somehow coherent with the R2 rule (see section 3.2.2), the gaming feature being based on information related to the learner or the learning content, as usefulness is perceived by the students for the global activity.

\subsubsection{Effects of Gaming Feature Adaptation}

The results of gaming feature enjoyment and usefulness perceived among the groups are reported in Figure 10. The effect size is reported in Table 7. The number of answers ( $\mathrm{n}=$ 21) differs from the total number of participants who had features $(n=34)$ due to the students missing when the survey was completed.

Table 7: $d$-value for the perceived usefulness and fun of gaming features across groups

\begin{tabular}{|c|c|c|c|c|c|c|}
\hline & \multicolumn{3}{|c|}{ My gaming feature was useful } & \multicolumn{3}{|c|}{ My gaming feature was fun } \\
\hline$<$ & Group A & Group B & Group C & Group A & Group B & Group C \\
\hline Group A & - & 0.98 & 0.08 & 1 & 0.87 & 0,64 \\
\hline Group B & 0.98 & 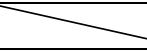 & -0.78 & -0.87 & & $-0,28$ \\
\hline Group C & -0.08 & 0.78 & & -0.64 & 0.28 & \\
\hline
\end{tabular}




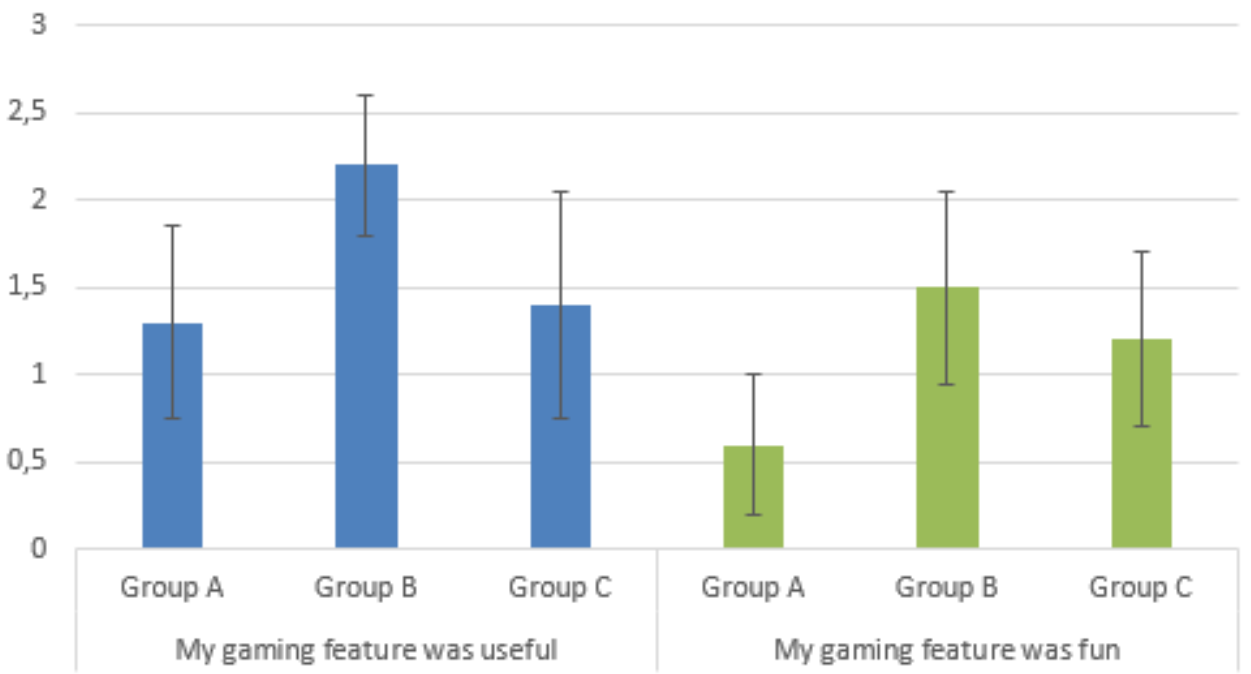

Figure 10: Perceived usefulness and fun of gaming features across groups

The members of the group with the worst adapted gaming features (B) reported finding their gaming features more useful $(\mathrm{m}=2.2)$ and more fun $(\mathrm{m}=1.5)$ than the one with the best adapted features (A). This is the contrary to what we expected. The effect is large, with a difference of 0.98 standard deviations for perceived usefulness and 0.87 for perceived fun. Meanwhile, the learners with random gaming features (C) reported rather the same usefulness that learners with adapted features $(\mathrm{A})$, but more fun $(\mathrm{m}=1.2)$. The effect is medium with a difference of 0.64 standard deviation. This indicates that the adaptation process might have a negative impact on the perceived usefulness and fun of adapted gaming features. We will discuss this observation in the conclusion.

\subsubsection{Effects of the Profiling Strategy}

At the end of the profiling experiment (group P), we ran the profiling algorithm on the trace of users' interactions with many different sets of values for $\mathrm{p}_{\mathrm{n}}, \mathrm{s}_{\mathrm{off}}$ and $\mathrm{s}_{\text {use. For the first }}$ test we used the medium value $(0.5)$ for $\mathrm{p}_{\mathrm{n}}$, and, as recommended in 3.4.2, a rather high value for $s_{\text {off }}(0.6)$ and a low value for $s_{\text {use }}(0.1)$. From this point onwards we made all parameters vary by steps of 0.1 and measured accuracy each time, until we found the most accurate set of values. The resulting optimal set of values is $\mathrm{p}_{\mathrm{n}}=0.3, \mathrm{~s}_{\mathrm{off}}=0.1, \mathrm{~s}_{\mathrm{use}}=0.1$. Table 8 presents the dominant player types predicted by the game adaptation engine with the first set of values and with the most optimal set. It also shows the number of predictions matching the results of the BrainHex survey.

Table 8: Dominant player type system prediction, and matches with the BrainHex survey

\begin{tabular}{|l|l|l|l|l|}
\hline & \multicolumn{2}{|l|}{$\mathrm{p}_{\mathrm{n}}=0.5, \mathrm{~s}_{\text {off }}=0.6, \mathrm{~s}_{\text {use }}=0.1$} & \multicolumn{2}{l|}{$\mathrm{p}_{\mathrm{n}}=0.3, \mathrm{~s}_{\text {off }}=0.1, \mathrm{~s}_{\text {use }}=0.1$} \\
\hline & Prediction & Match & Prediction & Match \\
\hline Seeker & 0 & 0 & 1 & 0 \\
\hline Survivor & 4 & 0 & 4 & 1 \\
\hline Daredevil & 3 & 1 & 0 & 0 \\
\hline Mastermind & 4 & 1 & 1 & 0 \\
\hline Conqueror & 3 & 3 & 7 & 3 \\
\hline Socializer & 2 & 0 & 3 & 3 \\
\hline Achiever & 1 & 0 & 1 & 0 \\
\hline Total & 17 & 5 & 17 & 7 \\
\hline
\end{tabular}


The first predictor got five matches with the dominant player type of the correct profile $(29 \%)$, while the second predictor made seven matches with the correct profile $(41 \%)$. Table 9 shows the accuracy of those predictors to a random profile predictor. With a random prediction, the result will be $14 \%$ in mean (100/7). So with the two presented sets of values, game engine prediction is better than a random prediction. Moreover, it shows that using interaction traces could bring complementary information compared to the single use of a survey. These results are encouraging and we discuss in part 5.4 some future directions to obtain more reliable results and a better prediction.

Table 9: Accuracy of the dominant player type predictions

\begin{tabular}{|l|l|}
\hline Player model predictor & Accuracy \\
\hline Random scores & 0.14 \\
\hline Engine $\left(\mathrm{p}_{\mathrm{n}}=0.5 ; \mathrm{s}_{\text {off }}=0.6 ; \mathrm{s}_{\text {use }}=0.1\right)$ & 0.29 \\
\hline Engine $\left(\mathrm{p}_{\mathrm{n}}=0.3 ; \mathrm{s}_{\text {off }}=0.1 ; \mathrm{s}_{\text {use }}=0.1\right)$ & 0.41 \\
\hline
\end{tabular}

\section{Discussion and Conclusion}

\subsection{Implications for Theory}

\subsubsection{Learners' Player Profile}

Based on the BrainHex typology (Nacke et al., 2011), our study first showed that learners have different player profiles (see section 4.4.1), as they also have different preferences for the proposed gaming features (see section 4.4.2). These results could explain why some studies on gamification show a negative impact on learners. For instance, Hanus and Fox (2015) showed that integration of a leaderboard and badges in a learning environment decreased learners' motivation and performances in the final exam. The explanation could be that these gaming features did not correspond to the participants' player profiles. More generally, we agree with Harviainen (2014) that some gaming elements motivate some learners but can also have a negative impact on other learners.

Our results are in line with research on player typologies, such as Bartle's classification (1996) and Ferro's player types (Ferro et al., 2013). However, we observe that there are still only a few contributions in this area that are not specific to certain game types. The BrainHex typology is a first attempt to propose a generic typology and we chose it mainly for this reason. While Bartle's typology could be a good choice for game adaptation in the context of a MMORPG, BrainHex seemed more appropriate for gamification, as if offers a wide range of game mechanics.

However, we observe that the profiles of the learners involved in our study do not have the same distribution as in the online survey conducted by the creators of BrainHex (BrainHex, 2011). In our opinion, the participants in our study have specific player profiles due to their age (middle school students aged from 14 to 15), as there were few Seekers and Masterminds. While several studies propose detailed statistics on gender variations in player types (Yee, 2005; Bateman, Lowenhaupt and Nacke, 2011), few studies provide results related to the players' age (Lim, Taylor and Gallacher, 2016). Further studies on users' player profiles need to be conducted to consider this variable. More generally, an open question remains on the possibility of a generic typology, and further studies have to be conducted considering variables such as age, type of environment and context. 


\subsubsection{Gaming Features Complexity}

Regarding our first research question on the complexity of gaming features, the results (see section 4.4.2) indicate that the learning environment is easy to use, but that it becomes more complicated when we add several gaming features. This tends to confirm that adding gaming features with all possible game mechanics is not a good strategy, especially when considering variety among players' preferences. Adaptation of gaming features is therefore an answer to this problem.

This result cannot be compared to other studies, as the level of complexity perceived by the students has not been evaluated. Several studies on gamification have been conducted using several game mechanics to show that gamification has a positive impact on learners' performances, motivation and participation (Domínguez, Saenz-de-Navarrete, de-Marcos, Fernández-Sanz, Pagés and Martínez-Herráiz, 2013; De Marcos, Garcia-Lopez and GarciaCabot, 2016). However, little information is provided on the number of gaming features proposed to learners, gamification being considered as a whole process and not as independent features added to the learning environment.

The results of our exploratory study could have significant implications on the gamification process, as they imply that the learning environment should propose only a few gaming features to learners to reduce its complexity level. Combined with the results for player preferences, it appears that adapting the gaming features to their profile could be the only way to reduce complexity while motivating all types of learners. More studies concerning the impact of the number of gaming features on perceived complexity are required to validate and generalize this observation.

\subsubsection{Adaptive Gamification and Perceived Usefulness and Fun}

Our third research question concerned the adaptation process and its impact on learners' perceived usefulness and fun of the gaming features. We expected learners with a gaming feature matching their player profile to perceive this feature as more fun and more useful than learners with a randomly selected or a counter-adaptive feature. However, the results show that learners with counter-adaptive features rated them as more fun and more useful. Meanwhile, this difference between groups tends to show that adaptation of gaming features does indeed have an impact on learners' perception. Otherwise the results would have been the same for all groups, as we observed when evaluating the different functionalities (see section 4.4.5). These results cannot be compared with other studies as, to the best of our knowledge, no other studies on adaptive gamification have been conducted to date.

One explanation for this result could be that learners who were provided with counteradapted features discovered game mechanics they were not used to playing with. Maybe this novelty could have led to better ratings. This suggestion might be supported by the fact that learners with random gaming features rated them as more fun than those who added adapted features. Lounis, Pramatari and Theotokis (2014) reported a rather same effect size $(d=.70)$ when adding a community collaboration game element to a system with one game element already. That suggests adding a collaboration game element for everyone may be similarly effective at making a system fun as the adaptive system we developed. However, these effect sizes are based on a rather low number of participants and cannot lead to a strong conclusion.

We can also question the validity of what exactly is measured when asking participants directly for their perceptions. In fact, we observe that the results from interaction traces are not the same as those from the questionnaire. For instance, learners "used" the leaderboard more than the other functionalities. However, they rated the three functionalities equally. We suggest that a gaming feature can have a positive impact on user's motivation and learning even if they do not perceive it explicitly as useful or fun. It would be interesting to use indirect measures as well to assess the effect on motivation, for example from 
predefined questionnaires, such as like the Situational Motivation Scale (Guay, Vallerand and Blanchard, 2000).

This suggestion is also supported by the fact that learners considered the features as more useful than fun, which is a surprising result for gaming features. We can also ask ourselves to what extent children are a good audience for gamification as they are more used to playing video games. It would be interesting to conduct the same type of experimentation with older participants. Another explanation is that these features are not adapted to these participants and it would therefore be interesting to test other features with them.

\subsection{Implications for Practice}

\subsubsection{Implementation of Adaptive Gamification}

One of the main contributions of this paper is the implementation of adaptive gamification that opens up new directions for research in the field. We introduced the concept of epiphytic gaming features to allow adaptive gamification of learning environments. Gamification is considered not only as a global process, but also as a flexible set of gaming features that can be added to or removed from the environment, thus allowing the adaptation process.

We also propose a set of rules to define epiphytic gaming features to help designers. These rules would need more implementations and tests to be considered as generic and complete, but they constitute a solid basis for such research. Several frameworks have been proposed to evaluate and improve the quality of serious games. In particular, the FourDimensional Framework of Fraitas and Olivier (2006) and the Applied Behavioral Analysis of Tan, Lin and Ting (2007) include practical recommendations that could be applied to gamification. Using such recommendations could lead to extended versions of the rules for designing gaming epiphytes, thus improving their quality.

We proposed a player model based on the BrainHex typology as well as adaptation rules and formulae for selecting the gaming features most adapted to the learners' player profile. Considering the player model, the majority of existing works on adaptation in games are based on Bartle's typology (Göbel et al., 2010, Challco et al., 2015, Gil, Cantador and Marczewski, 2015) although this typology is specific to MMORPG. As gamification can be applied to any non-game contexts (Deterding et al., 2011), the use of more generic classifications is required. The BrainHex typology appeared to be the most adapted to our context. However, player modeling is still a growing field of research, and other typologies could be more relevant for gamification adaptation in the future. In this case, our adaptation model could be used the same way with a new typology, as long as it works with a fixed number of player types and represents the player profile with a value for each type.

\subsubsection{Profiling Process and Gaming Features Design}

We showed that the profiling process is effective. This preliminary result is encouraging even if we have few cases. As there are seven player types, a random profile predictor would guess the correct dominant type in $100 / 7=14 \%$ of cases. Our profiling strategy based on users' interactions attained an accuracy of $29 \%$ with the first set of parameters, and could reach even higher values with training. Although the number of users is too small to perform meaningful statistical tests, this result suggests a relationship between the learners' actions on the gaming features and their player profile.

However, we think that the profiling process could be improved by a better integration of the gaming features in the learning environment, as the quality of a learning game is crucial for effective teaching (Van Eck, 2006). It is a fact that the use of gaming features does not depend only on users' interest in them, but also on the success of their implementation. all 
three features received similar rates concerning their usefulness and fun, but the bright stars and mnemonics features were barely used compared to the leaderboard. Understanding the reasons for this difference is crucial for the success of future design.

For the first feature (bright stars), the number of interactions per user is lower than one (see figure 8). This means that several users did not even notice that they could hover the stars. This observation tells us that interactions will be relevant for the profiling process only if they are obvious.

For the third feature, we observed that the few mnemonics proposed were very unclear or irrelevant. Accordingly, we assume the reason for their lack of use is that this feature was too complicated for the learners. They were probably spending more efforts in understanding the grammatical rules than in remembering them, and thus were not sufficiently skilled to propose mnemonics. These observations highlight the need to use gaming features that have already been tested in similar contexts as this ensures users do not need to try too hard when carrying out the main learning activity.

For the second feature (leaderboard), the number of "USE" interactions is high, which makes sense given the large number of conquerors. However, the number of "OFF" interactions is also high, as this feature was sometimes removed since it was placed in the middle of the screen. In such a case, the "OFF" interaction is not due to a negative perception of the game mechanics behind the gaming feature, as learners did not even take time to try it. Such a situation should be avoided, because it disturbs the profiling process. Globally, the presentation of a gaming feature has to be peripheral compared to the main activity.

\subsection{Limitations of the Study}

The study reported in this paper suffers from several limitations that need to be highlighted. Firstly, the findings cannot be generalized due to the small number of participants. Research on adaptive gamification is at an early stage, and the exploratory nature of the study we conducted offers new insights into this field. However, we implemented the adaptation process only in one specific context (middle school teaching) for a specific learning environment and with a limited number of participants. Therefore, we cannot validate experimentally the fact that it is indeed generic. Other studies need to be conducted in other contexts (e.g. distance learning or blended learning), at another level (e.g. high school or adult training) and on other learning environments. Also, studies with more participants would be required to confirm the results and validate them statistically.

Secondly, the number of gaming features in the experiment was probably too small. As each feature implements mechanics that suit several player types, three features were enough to match each player type. However, the users generally belong to several player types at once. Accordingly, more diversified features are required to match all the combinations of player types, especially with a seven types typology.

The design of the gaming features may also have had an impact on the results of the study. The features were not tailored for a specific kind of participants. We think the students would have perceived the features as more engaging and fun with more colours and/or animations. In fact, the students are used to play games and the design of the gaming features may have been perceived as "too serious". The Projet Voltaire environment is addressed first to adults in companies and we think the features may be more adapted for this kind of users.

Another limitation is due to the final questionnaire we submitted to learners. The perceived complexity of the system and the usefulness and fun of the gaming features are measured with single-items. According to the exploratory nature and the ecological conditions of our study, we chose these single-item measures to identify the impact of adaptive gamification with a short questionnaire. The impact of adaptive gamification on each of these factors should be validated with dedicated questionnaires. 
Regarding the questionnaires, we find low Cronbach's alpha values for the items of the BrainHex questionnaire we used. Our changes to adapt it to gamification concern half of the items and they are slight. For example, "Talking with other players, online or in the same room." became "Chatting about everything and nothing." The new item is still about talking with people (what Socializers like), but it does not refer to a gaming situation anymore. This difference introduces a new dimension between related items, which may drop the Cronbach's alpha, although the items are still related to the same player type. This drop in alpha values could also be due to the particular students that participated to the study. In fact, the BrainHex was tested on a large population, whereas we used it specifically with middle school pupils. Moreover, the items of the questionnaire might not correspond well to the gaming motivations of French people. So the questionnaire we used in our study could still predict the player types quite accurately, but it should be improved to be more consistent.

Finally, the process for assigning values to relate gaming features to player profiles is mainly based on our gamification expertise. We believe that researchers and practitioners interested in our approach will also have sufficient expertise to assign relevant weights, based on the examples we give in our implementation. Hints can also be found in the description of the player types, which generally indicates the kind of mechanics each player archetype will appreciate. However, the lack of a systematic technique to assign these values is a serious limit for reproducibility of the proposed approach. Incidentally, the risk of making mistakes implies a risk of "Garbage In Garbage Out": if the values are not properly determined, the adaptation process as well as the profiling process will fail.

\subsection{Future Directions for Research}

\subsubsection{Experimental work}

Although our sample sizes were rather small to perform meaningful statistical tests, to the best of our knowledge, this study is the first one to focus on adaptive gamification. We showed that adaptive gamification is feasible, although the efficiency of this approach has not yet been proven. Therefore, our main research priority is to conduct new experiments to validate the proposed model.

In the experiment presented in this paper, some results were contrary to our expectations. Future experiments should help us know whether it is a real trend, or due to our experimental settings. Such experiments should rely on more gaming features, in various contexts and learning environments. In particular, they need to include more participants in order to allow statistical validations.

To evaluate learners' engagement, we will conduct another experiment with distance learners in ecological conditions to compare the time spent on the learning activity between users with adapted and counter-adapted features. We will evaluate their motivation based on a questionnaire so as to obtain indirect measurements. Another option is to use the Item Response Theory (Beck, 2005) to evaluate learners' engagement based on the frequency of their answers. We also plan to cross the direct measures (asking the participants) with the indirect measures of engagement (time spent learning, motivation survey, traces of interactions), to find out whether users are aware of the effects of game mechanics on their engagement.

Besides, the relationship between the number of features and the perceived complexity of the system needs to be looked into more thoroughly. Using more varied numbers of features will show whether this relationship is linear, or rather logarithmic, quadratic, etc. The influence of gaming features design also needs to be better understood. 


\subsubsection{Theoretical work}

This approach paves the way for broad research that, however, still requires considerable efforts on several aspects: player modeling, design of adaptable gaming features, and an adaptation process for real-time adaptation based on learners' interactions with the environment. First, the table of relationships between the gaming features and player types is the key to the adaptation model, and thus deserves more attention. In this first experiment, we relied on our own experience to initialize its values. In recent research, we have established reliable values based on the expertise of gamification experts (Monterrat et al., 2015). A second approach could rely on data mining. If we collect data from sufficiently large number of users who interact with a list of gaming features, we could look for the relationships between the players' profiles and their frequency of interactions with the gaming features. The correlations between high "USE" frequencies and a specific player type could lead to high values in the relationships table.

Secondly, the proposed adaptation model can be improved by adapting the number of active gaming features, and not only selecting the most relevant feature for a user. Thus, users who are already motivated by the learning activity could have zero or one gaming feature, while users looking for funnier mechanics could have two or three features.

Our third research focus concerns the combination of the profiling process and the adaptation process to carry out dynamic adaptation. Relying on users' traces to predict their profile would be one way to avoid player type surveys, which can be used in experimental conditions but not in any learning situations. For this purpose, a richer trace model is probably required, with more interaction types than the "USE" and "OFF" we used here.

Finally, we think it would be interesting to consider the timing of feature activation in the model. If all the selected gaming features are activated at the beginning of the activity, users could get tired of using them, meaning they may cease to be efficient after a long period of using the environment. As a solution, activation of the gaming features could be staggered in time, in order to provide learners regularly with new game mechanics. 


\section{References}

Barata, G., Gama, S., Jorge, J., \& Gonçalves, D. (2013). Improving participation and learning with gamification. First International Conference on Gameful Design, Research, and Applications. New-York, USA, 2013, 10-17.

Bartle, R. (1996). Richard A. Bartle: Players Who Suit MUDs. Accessed July 3th 2016, at http://www.mud.co.uk/richard/hcds.htm\#1

Bateman, C., Lowenhaupt, R., \& Nacke, L. E. (2011). Player typology in theory and practice. In Proceedings of DiGRA 2011 Conference: Think Design Play. Hilversum, Netherlands.

Beck, J. (2005). Engagement tracing: using response times to model student disengagement. International Conference on Artificial Intelligence in Education (AIED 2005), The Netherlands, 2005, 88-95.

Bouvier P., Sehaba K. \& Lavoué E. (2014). A trace-based approach to identifying users' engagement and qualifying their engaged-behaviours in interactive systems: Application to a social game. User Modeling and User-Adapted Interaction (UMUAI), Vol. 24 (No. 5), 413451.

BrainHex.com (2011). Subclass Popularity. Accessed 11 July 2016 at http://blog.brainhex.com/2011/11/subclass-popularity.html.

Brusilovsky, P., \& Millán, E. (2007). User models for adaptive hypermedia and adaptive educational systems. The adaptive web, Brusilovsky, P., Kobsa, A. \& Nejdl, W. (Eds), Springer LNCS, 3-53.

Busch, M., Mattheiss, E., Orji, R., Fröhlich, P., Lankes, M., \& Tscheligi, M. (2016). Player Type Models: Towards Empirical Validation. In Proceedings of the 2016 CHI Conference Extended Abstracts on Human Factors in Computing Systems, 1835-1841. ACM Press. https://doi.org/10.1145/2851581.2892399

Caillois, R. (1961). Man, Play, and Games. The free press, New York.

Challco, G. C., Moreira, D. A., Mizoguchi, R., \& Isotani, S. (2014). An Ontology

Engineering Approach to Gamify Collaborative Learning Scenarios. In CYTED-RITOS

International Workshop on Groupware 185 198. Cham: Springer International Publishing. Cheng, L.-T., Shami, S., Casey, D., Muller, M., DiMicco, J., Patterson, J., Rohall, S., Sempere, A., Geyer, W. (2011). Finding moments of play at work. In CHI 2011 Workshop, Vancouver, Canada, 7-12 May 2011, (4p.).

Cohen, J. (1977). Statistical power analysis for the behavioral sciences. Routledge. Conley, K., \& Donaldson, C. (2015). Gamification: The Measurement of Benefits. Gamification in Education and Business. Reiners T. \& Wood L. C. (Eds), Springer, 673-688. Desmarais, M. C., Beheshti, B., \& Naceur, R. (2012). Item to skills mapping: deriving a conjunctive q-matrix from data. In Intelligent Tutoring Systems, 454-463. Springer.

Deterding, S., Dixon, D., Khaled, R., \& Nacke, L. (2011). From game design elements to gamefulness: defining gamification. In Proceedings of the 15th International Academic MindTrek Conference: Envisioning Future Media Environments (MindTrek 2011), Tampere, Finland, 9-15.

Da Rocha Seixas, L., Gomes, A. S., \& de Melo Filho, I. J. (2016). Effectiveness of gamification in the engagement of students. Computers in Human Behavior, Vol. 58, 48-63. http://doi.org/10.1016/j.chb.2015.11.021

Domínguez, A., Saenz-de-Navarrete, J., de-Marcos, L., Fernández-Sanz, L., Pagés, C., and Martínez-Herráiz, J.-J. (2013). Gamifying learning experiences: Practical implications and outcomes. Computers \& Education, 63, 380-392.

Fenouillet, F., \& Tomeh, B. (1998). La motivation agit-elle sur la mémoire. Éducation permanente, Vol. 136 (No. 10), 37-45.

Ferro, L. S., Walz, S. P., \& Greuter, S. (2013). Towards personalised, gamified systems: an investigation into game design, personality and player typologies. 9th Australasian 
Conference on Interactive Entertainment: Matters of Life and Death (IE 2013), Melbourne, VIC, Australia, (7 p.).

de Freitas, S., \& Oliver, M. (2006). How can exploratory learning with games and simulations within the curriculum be most effectively evaluated? Computers \& Education, Vol. 46 (No. 3), 249 264. http://doi.org/10.1016/j.compedu.2005.11.007

Gauch, S., Speretta, M., Chandramouli, A., \& Micarelli, A. (2007). User profiles for personalized information access. The adaptive web, Brusilovsky, P., Kobsa, A. \& Nejdl, W. (Eds), Springer LNCS, 54-89.

Gil, B., Cantador, I., \& Marczewski, A. (2015). Validating Gamification Mechanics and Player Types in an E-learning Environment. In Design for Teaching and Learning in a Networked World, Vol. 9307, 568-572. Cham: Springer International Publishing. Giroux, S., Pachet, F., Paquette, G., \& Girard, J. (1995). Des systèmes conseillers épiphytes. Revue d'intelligence artificielle, Vol. 9 (No. 2), 165-190.

Göbel, S., Wendel, V., Ritter, C., \& Steinmetz, R. (2010). Personalized, adaptive digital educational games using narrative game-based learning objects. $5^{\text {th }}$ International Conference on Entertainment for Education. Changchun, China, 16-18 august 2010, 438-445.

Guay, F., Vallerand, R. J., \& Blanchard, C. (2000). On the assessment of situational intrinsic and extrinsic motivation: The Situational Motivation Scale (SIMS). Motivation and Emotion, Vo. 24 No. 3, 175-213.

Hamari, J., Koivisto, J., \& Sarsa, H. (2014). Does Gamification Work?-A Literature Review of Empirical Studies on Gamification. 47th Hawaii International Conference on System Sciences. Hawaii, USA, 2014, 3025-3034.

Hamari, J. (2015). Do badges increase user activity? A field experiment on the effects of gamification. Computers in Human Behavior. http://doi.org/10.1016/j.chb.2015.03.036. Hanus, M. D., \& Fox, J. (2015). Assessing the effects of gamification in the classroom: A longitudinal study on intrinsic motivation, social comparison, satisfaction, effort, and academic performance. Computers \& Education, Vol. 80, 152-161.

http://doi.org/10.1016/j.compedu.2014.08.019.

Harviainen, J. T. (2014). Critical challenges to gamifying education: A review of central concepts. In Proceedings of the Game On! Conference, May 22-23, 2014, Moscow, The Russian Federation.

Hunicke, R., LeBlanc, M., \& Zubek, R. (2004). MDA: A formal approach to game design and game research. In Proceedings of the AAAI Workshop on Challenges in Game AI, Vol. 4, 1-5. Kapp, K. M. (2012). The Gamification of Learning and Instruction: Game-based Methods and Strategies for Training and Education. John Wiley \& Sons.

Landers, R. N. (2015). Developing a theory of gamified learning: Linking serious games and gamification of learning. Simulation \& Gaming, Vol. 45, 752-768.

Landers, R. N., Bauer, K. N., \& Callan, R. C. (2015). Gamification of task performance with leaderboards: A goal setting experiment. Computers in Human Behavior.

http://doi.org/10.1016/j.chb.2015.08.008

Lim, M. Y., Taylor, N. K., \& Gallacher, S. M. (2016). Gamification of Tour Experiences with Motivational Intelligent Technologies. International Journal on Advances in Intelligent

Systems, Vol. 9 (No. 1\&2)

Linehan, C., Kirman, B., Lawson, S., \& Chan, G. (2011). Practical, appropriate, empiricallyvalidated guidelines for designing educational games. In Proceedings of the SIGCHI Conference on Human Factors in Computing Systems 1979-1988. ACM.

Lounis, S., Pramatari, K., \& Theotokis, A. (2014). Gamification is all about fun: The role of incentive type and community collaboration. European Conference on Information Systems (ECIS 2014), Tel Aviv, Israel, p. 1-14. 
McCallum, S. (2012). Gamification and serious games for personalized health. Stud Health Technol Inform, Vol. 177, 85-96.

Mobasher, B. (2007). Data mining for web personalization. The adaptive web, Brusilovsky, P., Kobsa, A. \& Nejdl, W. (Eds), Springer LNCS, 90-135.

Monterrat, B., Desmarais, M., Lavoué, E., \& George, S. (2015). A player model for adaptive gamification in learning environments. In Proceedings of International Conference on Artificial Intelligence in Education (AIED) 297-306. Springer International Publishing. Nacke, L. E., Bateman, C., \& Mandryk, R. L. (2011). BrainHex: Preliminary Results from a Neurobiological Gamer Typology Survey. In ICEC 288-293. Springer.

Nacke, L. E., Bateman, C., \& Mandryk, R. L. (2014). BrainHex: A neurobiological gamer typology survey. Entertainment Computing, Vol. 5 (No. 1), 5562.

https://doi.org/10.1016/j.entcom.2013.06.002

Orji, R., Mandryk, R. L., Vassileva, J., \& Gerling, K. M. (2013). Tailoring persuasive health games to gamer type. In Proceedings of the SIGCHI Conference on Human Factors in Computing Systems 2467-2476. ACM.

Pachet, F., Giroux, S., \& Paquette, G. (1994). Pluggable Advisors as Epiphyte Systems. In Calisce 194 (Computer Aided Learning in Science and Engineering), Paris, 167-174.

Robinson, D., \& Bellotti, V. (2013). A preliminary taxonomy of gamification elements for varying anticipated commitment. In ACM CHI 2013 Workshop on Designing Gamification:

Creating Gameful and Playful Experiences.

Sailer, M. (2013). Psychological Perspectives on Motivation Through Gamification.

Interaction Design and Architecture(s) Journal - IxD\&A, 28-37.

Seaborn, K., \& Fels, D. I. (2015). Gamification in theory and action: A survey. International Journal of Human-Computer Studies, Vol. 74, 1431.

http://doi.org/10.1016/j.ijhcs.2014.09.006

Su, C.-H., \& Cheng, C.-H. (2015). A mobile gamification learning system for improving the learning motivation and achievements. Journal of Computer Assisted Learning, Vol. 31 (No. 3), 268-286.

Thue, D., Bulitko, V., Spetch, M., \& Wasylishen, E. (2007). Interactive Storytelling: A Player Modelling Approach. Proceedings of the 3rd Artificial Intelligence and Interactive Digital Entertainment Conference (AIIDE), 2013, 43-48.

Van Eck, R. (2006). Digital game-based learning: It's not just the digital natives who are restless. EDUCAUSE review, Vol. 41 (No. 2), p. 16.

Vassileva, J. (2012). Motivating participation in social computing applications: a user modeling per spective. User Modeling and User-Adapted Interaction, 22(1-2), 177-201. Yee, N. (2005). Motivations of Play in MMORPGs. In Proceedings of the Digital Games Research Association Conference (DiGRA), Vancouver, Canada.

Yee, N. (2006). Motivations for play in online games. CyberPsychology \& Behavior, Vol. 9 (No. 6), 772-775. 


\section{Appendix: BrainHex survey used for experiment}

(Information in brackets is here for the reader, is was not provided for the participants in the survey.)

Dites comment vous appréciez les situations suivantes en notant "Oui j'adore ça !" [+2], "J'aime bien." [+1], "Pourquoi pas." [0], "Bof." [-2], "Non, pas pour moi !" [-4].

- $\quad$ [Seek] Me balader sans savoir sur quoi je vais tomber.

- $\quad$ [Surv] Fuir un dangereux ennemi.

- $\quad$ [Dare] Éviter des obstacles de justesse en allant à toute vitesse.

- $\quad$ [Mast] Résoudre une énigme.

- [Conq] Jouer 1 contre 1 avec un ami, et le battre.

- $\quad$ [Soci] "Chatter" en ligne.

- $\quad$ [Achi] Dans un jeu, explorer chaque recoin pour être sûr que je n'ai rien raté.

- $\quad$ [Dare] Être sur le point de battre mon record à un jeu.

- $\quad$ [Mast] Trouver la bonne stratégie.

- $\quad$ [Conq] Prendre le dessus sur un adversaire très fort pendant un match.

- [Soci] Jouer avec des gens que je ne connais pas.

- [Achi] Trouver le dernier objet qu'il manquait pour compléter une collection.

- [Seek] Simplement regarder le paysage et les gens qui passent.

- $\quad$ [Surv] Être terrifié.

- $\quad$ [Conq] Réussir un défi après avoir échoué plusieurs fois.

- [Soci] Aider quelqu'un qui n'a pas compris.

- [Achi] Passer de 99\% à 100\% de progression.

- [Seek] Découvrir enfin ce qu'il y a derrière une porte qui était fermée à clé.

- $\quad$ [Surv] Être bien caché quand un ennemi passe tout près de moi.

- $\quad$ [Dare] Prendre des risques.

- [Mast] Trouver la solution à un problème tout seul.

Classez ces actions de 1 à 7 points : 1 pour ce qui vous intéresse le moins et 7 pour l'action que vous préférez. [Scores from 2 to 14, randomized items].

- [Achi] Réaliser un objectif que je m'étais fixé il y a très longtemps.

- $\quad$ [Seek] M'émerveiller devant la beauté époustouflante.

- [Surv] Sentir que mon cœur va s'arrêter tellement j'ai eu peur.

- [Dare] Avoir le souffle coupé par une vitesse vertigineuse.

- [Mast] Avoir le déclic pour réussir un casse-tête difficile.

- $\quad$ [Conq] Savourer ma victoire après un long combat.

- $\quad$ [Soci] Se comprendre tellement bien avec une autre personne qu'un seul regard suffit pour être d'accord. 